\title{
HUBUNGAN KUALITAS TIDUR DENGAN PERUBAHAN TEKANAN DARAH IBU HAMIL DI RUMAH BERSALIN BIDAN NURIL
}

\author{
Hermeksi Rahayu, Dwi Kustriyanti, Okta Indra \\ Stikes Karya Husada, Jl. KompolR Soekanto No 46, (024) 6724581 \\ rahayuhermeksi@gmail.com
}

\begin{abstract}
ABSTRAK
Hipertensi kehamilan dialamai $8 \%$ pada ibu hamil yang merupakan penyebab kematian ibu dan neonates serta beresiko mengalami eklampsia dan pre eklampsia. Tekanan darah yang tinggi selama kehamilan dapat mempengaruhi kualitas tidur. Insomnia dialami $12 \%$ ibu hamil trimester pertama dan sebanyak $75 \%$ pada akhir kehamilan. Penelitian ini bertujuan mengetahui hubungan kualitas tidur terhadap perubahan tekanan darah ibu hamil di Rumah Bersalin Bidan Nuril. Desain penelitian ini menggunakan pendekatan cross sectional pada 42 ibu hamil trimester III yang diukur tekanan darah dan kualitas tidur menggunakan instrument Pittsburg Sleep Quality Index (PSQI). Hasil penelitian ini didapatkan rata-rata kualitas tidur 5,78 dan p value systole sebesar 0,002 dan diastole 0,024 menggunakan uji Rank Speramen test. Ada hubungan antara kualitas tidur pada ibu hamil terhadap perubahan tekanan darah baik systole maupun diastole di Rumah Bersalin Bidan Nuril.
\end{abstract}

Kata kunci: kehamilan; kualitas tidur; tekanan darah

\section{RELATIONSHIP OF QUALITY OF SLEEP AND CHANGES OF BLOOD PRESSURE OF PREGNANT WOMEN IN NURIL MATERNAL CLINIC}

\begin{abstract}
Pregnancy hypertension is experienced by $8 \%$ of pregnant women which is the cause of mortality maternal and neonatal that can at risk of experiencing eclampsia and pre-eclampsia. High blood pressure during pregnancy can affect sleep quality. Sleep disturbance is experiencing $12 \%$ of pregnant women in the first trimester and as much as $75 \%$ at the end of pregnancy. This study aims was to see the relationship between sleep quality and changes in blood pressure of pregnant women at Nuril Maternal Clinic. This study was a cross-sectional study design with 42 third trimester pregnant womenwho measured blood pressure and sleep quality using the Pittsburg Sleep Quality Index (PSQI). The results showed that the average sleep quality was 5.78 and the Pvalue systole was 0.002 and diastole was 0.024 using the Speramen Rank test. There was a relationship between the quality of sleep in pregnant women to changes in blood pressure, both systole and diastole at the Nuril Maternal Clinic..
\end{abstract}

Key words: pregnancy; sleep quality; blood pressure

Jurnal SMART Keperawatan is licensed under a Creative Commons Attribution-ShareAlike 4.0 International License. 


\section{LATAR BELAKANG}

Kehamilan adalah Periode dimana terjadi perubahan-perubahan di seluruh sistem tubuh, yang meliputi kardiovaskular, pernapasan, hormonal, gastrointestinal, maupun sistem muskuloskletal (Sindu, 2014).Penyebab kematian ibu karena hipertensi cenderung meningkat sebanyak $35 \%$, dan penyebab lain adalah perdarahan 17\%, infeksi $8 \%$ dan lainlain sebanyak 40\% (Dinkes, 2018). Prevalensi kematian ibu disebabkan karena preeklamsi sebanyak 34\%. Salah satu gejala preeklamsi pada ibu hamil ditandai dengan adanya peningkatan tekanan darah.

Perubahan tekanan darah pada ibu hamil dapat disebabkan adanya perubahan pola tidur. Kualitas tidur yang buruk dapat menyebabkan kejadian kelahiran preterm, retriksi pertumbuhan intra-uterin, gawat janin, asfiksia, aspirasi mekonium, serta lebih rentan menderita hipertensi gestasional, preeklampsia, diabetes melitus dan waktu melahirkan lebih lama dibandingkan dengan ibu hamil yang memiliki kualitas tidur baik (Zaky, 2015). Dampak buruk dari tidur bagi kesehatan dapat mengakibatkan depresi, kurang konsentrasi dalam beraktivitas, gangguan pembelajaran verbal, gangguan memori, menggangu artikulasi bicara, gangguan penginderaan, stress, gangguan motorik, peningkatan denyut jantung dan hipertensi. Stress, depresi dan hipertensi terjadi pada wanita hamil dapat mengakibatkan prematur dan Bayi Berat Badan Lahir Rendah (BBLR), preeklamsi pada ibu hamil bahkan bisa mengakibatkan terjadinya abortus pada bayi (Pieter, 2013; Sharma, et al. 2016)).

Faktor-faktor yang mempengaruhi perubahan tekanan darah adalah genetik, imunologis, primiparitas, usia gestasional, faktor terkait kehamilan, penyakit ibu, faktor lingkungan, dan stress (Sindu, 2014). Penelitian sebelumnya oleh O' Brien et al. (2014) dan Salah satu komponen dari penilaian kualitas tidur yaitu gangguan tidur seperti mendengkur atau sleep obstructive apnea yang terjadi pada ibu hamil dapat meningkatkan risiko terjadinya hipertensi dalam kehamilan. Hal ini terjadi akibat hipoksia intermiten dan tidur yang terfragmentasi yang akhirnya menyebabkan peningkatan respon inflamasi tubuh, dimana respon inflamasi memiliki peran dalam terjadinya hipertensi dalam kehamilan (Sharma, 2016).

Survey pendahuluan di dapatkan di Rumah Bersalin Bidan Nuril pada bulan Januari-September 2019 ibu hamil yang menjalani perawatan sebanyak 176 pasien. Dari studi wawancara secara langsung terhadap 10 ibu hamil $60 \%$ diantaranya mengalami tekanan darah tinggi dan 40\% diantaranya mempunyai tekanan darah normal, ibu yang mempunyai tekanan darah tinggi mengatakan sering cemas terhadap kehamilannya, ibu mengatakan tidurnya tidak nyenyak sering terbangun saat tidur malam hari.

Berdasarkan fenomena diatas tersebut, maka dilakukan penelitian untuk mengetahui hubungan kualitas tidur dengan perubahan tekanan darah ibu hamil di Rumah Bersalin Bidan Nuril"

\section{METODE}

Penelitian ini dilakukan di Rumah Bersalin Bidan Nuril Gunungpati Semarang bulan Juni 2020 Agustus 2020. Desain penelitian yang digunakan kuantitatif dengan metode pendekatan cross sectional. Populasi dalam penelitian ini adalah 42 responden.Teknik pengambilan sampel yang digunakan adalah purposive sampling. Kriteria inklusinya adalah Ibu hamil trimester III dengan umur 20-35 tahun.Penelitian ini dengan nomor etik 771/KH.KEPK/KT/VIII/2020. Alat pengumpul data menggunakan kuesioner Pittsburg Sleep Quality Instrument (PSQI) dan pengukuran tekanan darah menggunakan spignomanometer digital. Analisis menggunakan Rank Spearman Test.

\section{HASIL}

Hasil yang didapatkan adalah mengenai karakteristik ibu hamil yang berkunjung ke Rumah Bersalin Nuril 
Tabel 1 Karakteristik ibu hamil di Rumah Bersalin Bidan Nuril ( $n=42)$

\begin{tabular}{lcccc}
\hline Karakteristik & F & $\%$ & Mean士SD & $\begin{array}{c}\text { Min- } \\
\text { Max }\end{array}$ \\
\hline Umur ibu & - & - & $\begin{array}{c}28.17 \pm 7.3 \\
3\end{array}$ & $17-43$ \\
\hline Pekerjaan: & & & & \\
Bekerja & 18 & 42.9 & - & - \\
IRT & 24 & 57.1 & & \\
\hline Pendidikan: & & & & \\
PT & 7 & 16.7 & & - \\
Menengah & 21 & 50.0 & - & \\
Dasar & 14 & 33.3 & & \\
\hline
\end{tabular}

Berdasarkan tabel 1. di atas maka dapat diketahui bahwa rata-rata usiaibuhamil 28.17 tahun, mayoritas sebagai ibu rumah tangga $57.1 \%$.

Tabel 2. Gambaran kualitas tidur dan tekanan darah sistolik dan distolik pada ibu hamil di Rumah Bersalin Bidan Nuril ( $n=42$ ).

\begin{tabular}{lcc}
\hline \multicolumn{1}{c}{ Variabel } & Mean \pm SD & $\begin{array}{c}\text { Min- } \\
\text { Max }\end{array}$ \\
\hline Kualitas Tidur & $5.79 \pm 1.180$ & $4-9$ \\
Kualitas tidur subjektif & $0.81 \pm 0.552$ & $0-2$ \\
Latensi tidur & $1.05 \pm 0.764$ & $0-3$ \\
DurasiTidur & $1.05 \pm 0.439$ & $0-2$ \\
Efisiensi kebiasaan & $0.26 \pm 0.767$ & $0-3$ \\
tidur & $1.19 \pm 0.455$ & $0-2$ \\
Gangguan tidur & $1.07 \pm 0.463$ & $0-2$ \\
Penggunaan obat & & $0-3$ \\
tidur & $0.36 \pm 0.850$ & \\
Disfungsi siang hari & & $75-90$ \\
\hline Tekanan darah & $82.3 \pm 4.650$ & $110-$ \\
\hline Sistolik & $120.6 \pm 10.07$ & 141 \\
\hline Diastolik & &
\end{tabular}

Berdasarkan tabel 2. maka dapat diketahui mean PSQI skor 5.79 dimana mayoritas mengalami masalah pada komponen sleep disturbance (1.19) dan use of deeping medication (1.07). Sedangkan mean tekanan darah sistolik dan diastolik ibu hamil 82.29 dan $120.57 \mathrm{mmHg}$.
Tabel 3. Hubungan kualitas tidur terhadap tekanan darah sistolik \& diastolic $(n=42)$

\begin{tabular}{lccc}
\hline & \multicolumn{3}{c}{ Tekanan darah } \\
\cline { 2 - 4 } & & Sistolik & Diastolik \\
\hline Kualitas Tidur & $\mathrm{R}$ & 0.349 & 0.455 \\
& $\mathrm{P}$ & 0.024 & 0.002 \\
\hline
\end{tabular}

Uji korelasi Spearman

\section{PEMBAHASAN}

Ibuhamil yang mengalami gangguan tidur ratarata berumur 28,17tahun di trimester ketiga. Gangguan tidur merupakan masalah yang sering muncul selama periode kehamilan (Facco, 2010). Faktor yang mempengaruhi kuaitas tidur diantaranya adalah stres, lingkungan, ras, usia dan riwayat kesehatan (Kathryn, 2017). Beberapa studi mengatakan bahwa waktu tidur yang pendek berhubungan dengan status kehamilan yang buruk (Facco, 2010; Williams, 2010).

Kualitas tidur ibu hamil dalam penelitian ini memiliki kualitas tidur yang buruk rata-rata 5.79.Durasi tidur bukan satu-satunya yang dapat mengukur kualitas tidur. Ada beberapa komponen yang diukur untuk mengetahui kualitas tidur seperti latensi, gangguan tidur, penggunaan obat dan day time dysfunction (Hancy, 2014; Volcovich, 2015). Kualitas tidur yang buruk akan menyebabkan system syaraf simpatis dan para simpatis menjadi tidak seimbang, sehingga memicu terjadinya peningkatan tekanan darah (Nansi, 2015).

Ibu hamil yang memiliki hipertensi gestasional, tekanan darah sebagai indicator untuk mendeteksi factor risiko pada kehamilan kedua dan beresiko kelahiran preterm (Laughon, 2014; Boghossianet al., 2015). Penelitian ini sebanyak 35,71\% ibu hamil yang memiliki tekanan systole diatas $120 \mathrm{mmHg}$ dan $50 \%$ memiliki tekanan diastole diatas $80 \mathrm{mmHg}$. Peningkatan tekanan diastole dan diastolic selama kehamilan beresiko mengalami preeklampsia (Schaaf, 2013; Zaky, 2015).

Tidur melibatkan suatu urutan keadaan fisiologis yang dipertahankan oleh integrasi tinggi aktivitas sistem saraf pusat yang berhubungan dengan perubahan dalam sistem saraf periferal, endokrin, kardiovaskular, 
pernafasan dan muscular (Smeltzer, 2010). Kontrol dan pengaturan tidur tergantung pada hubungan antara dua mekanisme serebral yang mengaktivasi secara intermitten dan menekan pusat otak tertinggi untuk mengontrol tidur dan terjaga (Zaky, 2015).

Sebuah mekanisme menyebabkan terjaga dan yang lain menyebabkan tertidur. Dua sistem dalam batang otak, Sistem Aktivasi Retikular (SAR) dan Regio Sinkronisasi Bulbar (BSR), diketahui bekerja sama untuk mengontrol siklus alami dari tidur. Formasi retikular ditemukan didalam batang otak yang akan menyampaikan keatas melalui medulla, pons, otak tengah, dan kedalam hipotalamus (Hani, 2011; Smeltzer, 2010).

Perubahan tekanan darah dalam kehamilan merupakan gejala klinis yang belum diketahui penyebab pastinya sampai saat ini, namun terdapat faktor-faktor yang dapat mempengaruhi kejadian fisiologi ini. Faktorfaktor tersebut adalah genetik, imunologis, primiparitas, usia gestasional, faktor terkait kehamilan, penyakit ibu, faktor lingkungan, dan stress (Lewis, 2014; Grandner, 2015; Haas, 2015).

Temuan dalam penelitian ini bahwa kualitas tidur berhubungan dengan tekanan sistolik dan diastolic pada ibu hamil. Peningkatan tekanan sistolik dan diastolic lebih dari normal merupakan indikator hipertensi dalam kehamilan. Tekanan darah tinggi atau hipertensi pada ibu hamil dapat berdampak pada pertumbuhan janin yang tidak sempurna, prematur, lahir dengan berat rendah, bahkan kematian ibu dan bayi (ACOG, 2011; Wells, 2011; Mannisto, 2013).

Pada ibu hamil yang menderita hipertensi, kecemasan yang dirasakan dapat mempengaruhi kondisi psikologis ibu bahkan sampai ke kondisi janin. Ibu hamil yang merasa cemas dalam menghadapi persalinan diperkirakan 40\% kecemasan merupakan gangguan psikologis yang dapat mempengaruhi kelancaran proses persalinan (Janiwarti, 2013; Lewis, 2014).

Gangguan tidur yang secara terus menerus akan mengakibatkan perubahan fisiologis tubuh berupa ketidakseimbangan homeostasis tubuh. Jika hal tersebut terjadi, maka sistem saraf simpatis akan diaktifkan oleh hipotalamus sebagai efek dari ketidakseimbangan homeostasis tubuh. Sehingga sistem saraf simpatis yang aktif, akan megakibatkan peningkatan tahanan perifer dan peningkatan curah jantung sehingga yang dapat mengakibatkan tekanan darah meningkat. Jadi dapat disimpulkan bahwa seseorang yang memiliki kualitas tidur buruk akan mengalami perubahan tekanan darah (Sharma, 2016).

\section{KESIMPULAN DAN SARAN}

Kualitas tidur hamil di Rumah Bersalin Bidan Nuril mempunyai median 6, std.deviasi 1.17 , dan skor terendah 4 tertinggi 9 . Tekanan darah sistolik ibu hamil di Rumah Bersalin Bidan Nuril mempunyai median 115 , std.deviasi 10.07 , dan tekanan darah sistolik terendah 110 tertinggi 141. Sedangkan tekanan darah diastolik ibu hamil di Rumah Bersalin Bidan Nuril mempunyai median 85, std.deviasi 4.65, dan tekanan darah diastolik terendah 75 tertinggi 90. Ada hubungan antara kualitas tidur pada ibu hamil terhadap tekanan darah sistolik dan tekanan diastolic di Rumah Bersalin Bidan Nuril dengan nilai $p$ value sebesar 0,002 dan 0,024.

Bagi Rumah Bersalin Bidan Nuril, hasil penelitian ini dapat dijadikan masukkan bagi BPM Nuril untuk dapat mensosialisaikan pentingnya manfaat tidur bagi ibu hamil sehingga tidak mempengaruhi perubahan tekanan darah. Bagi ibu hamil semoga penelitian yang sudah dilakukan memberikan informasi yang bermanfaat guna menekan kejadian hipertensi pada ibu hamil sehingga ibu dapat menghindarinya dengan cara menjaga kualitas tidur

\section{REFERENSI}

Facco FL, Kramer J, Ho KH, Zee PC, Grobman WA. (2010). Sleep disturbances in pregnancy.Obstet Gynecol. 115(1): 77-83.

Facco FL, Grobman WA, Kramer J, Ho KH, Zee PC. (2010). Self-reported short sleep duration and frequent snoring in 
pregnancy: impact on glucose metabolism. Am J Obstet Gynecol. 203(2): 142.el-142.35.

Grandner MA, Willams NJ, Knutson KL, Robert D, Jean-Louis G. (2015). Sleep disparity, race/ethnicity, and socioeconomic position. Sleep Med. 18;7-18.

Hancy A, Buysse DJ, Rosario BL, Chen YF, Okun ML. (2014). Sleep disturbance and cardiometabolic risk factors in early pregnancy: a preliminary study. Sleep Med. 2014; 15(4): 444-450.

Haas DM, Parker CB, Wing DA, et al. NuMoM2b study. A description of the methods of the nulliparous pregnancy outcomes study: monitoring mothers to be (NuMuM2B). Am J Obstet Gynecol. (2015); 212(4): 539.el-539.e24.

Hani, U., dkk. (2011). Asuhan kebidanan pada kehamilan fisiologis. Jakarta: Salemba Medika.

Janiwarty \& Pieter. (2013). Pendidikan Psikologi untuk bidan suatu teori dan terapannya. Yogyakarta: Repha Publishing.

Kathryn J et al. (2017). Sleep during pregnancy: The nuMoM2b pregnancy and sleep duration and continuity study. Sleep.Vol.XX. No. X.

Laughon SK, Albert PS, Leishear K, Mendola P. The NICHD consecutive pregnancies study: recurrent preterm delivery by subtype. Am. J Obstet Gynecol. (2014); 201: 131.e1-131.e8.

Lewis, Dirksen, Heitkemper, \& Bucher. (2014). Medical surgical nursing. assessment and mangement of clinical problems (9th edition). St. Louis : Mosby.

Mannisto T, Mendola P. (2013). Elevated blood pressure in pregnancy and subsequent chronic disease risk. Circulation. 2013; 127: 681-690.
Schaaf JM, Liem SM, Mol BW, Abu-Hanna A, Ravelli AC. (2013). Ethnic and racial disparities in the risk of preterm birth: a systematic review and meta-analysis. Am J Perinatol. 2013; 30(6): 433-450.

Sharma SK et al. (2016). Sleep disorders in pregnancy and their association with pregnancy outcomes: a prospective observational study. Sleep and Breathing Journal. 2016; 20(1):87-93. 2016

Smeltzer , S. C., \& Bare, B. G. Brunner \&Suddarth. (2010). Textbook of MedicalSurgical Nursing-12th edition. Philadelphia: Wolters Kluwer Health/ Lippincott Williams \& Wilkins.

Sindhu , P. (2014). Yoga untuk kehamilan edisi yang diperkaya sehat, Bahagia, dan penuh makna. Bandung: Qanit.

Volcovich E, Tikotzky L, Manber R. (2015). Objective and subjective sleep during pregnancy: links with depressive and anxiety symptoms. Arch Womens Ment Health. (2015); 19(1): 173-181.

Wells EM, Navas-Acien A, Herbstman JB, Apelberg BJ, Silbergeld EK, Caldwell KL, Jones RL, Halden RV, Witter FR, Goldman LR. Low-level lead exposure and elevations in blood pressure during pregnancy. Environ Health Perspect. (2011); 119:664-669.

Williams MA, Miller RS, Qiu C, Cripe Sm, Gelaye B, Enquobahrie D. Associations of early pregnancy sleep duration with trimester-specific blood pressures and hypertensive disorders in pregnancy. Sleep.(2010);33(10): 1363-1371.

Zaky NH. (2015). The relationship between quality of sleep during pregnancy and birth outcome among primiparae. International Organization of Scientific Research-Journal of Nursing and Health Science. 